\title{
A study on investors' personality characteristics and behavioral biases: Conservatism bias and availability bias in the Tehran Stock Exchange
}

\author{
Mahmoud Moradi $^{\mathbf{a}^{*}}$, Mehdi Meshki $\mathbf{b}^{\mathbf{b}^{*}}$ and Zeinab Mostafaei ${ }^{\mathbf{c}^{*}}$
}

${ }^{a}$ Assist.Prof. \& Faculty Member, Department of Management, University of Guilan, Rasht, Iran

${ }^{b}$ Assist.Prof. \& Faculty Member, Department of Accounting, Payame Noor University, Rasht, Iran

${ }^{c}$ M.A. Student, Department of Management (MBA), University of Guilan (International Pardis), Rasht, Iran

C H R O N I C L E

Article history:

Received October 20, 2012

Received in revised format

19 February 2013

Accepted 28 February 2013

Available online

March 12013

Keywords:

Behavioral Finance

Personality

Conservatism Bias

Availability Bias

\section{A B S T R A C T}

\begin{abstract}
Most economic and finance theories are based on the assumption that during economic decision making, people would act totally rational and consider all available information. Nevertheless, behavioral finance focuses on studying of the role of psychological factors on economic participants' behavior. The study shows that in real-world environment, people are influenced by emotional and cognitive errors and may make irrational financial decisions. In many cases, the participants of financial markets are not aware of their talents for error in decision making, so they are dissatisfied with their investments by considering some behavioral biases decisions. These decisions may often yield undesirable outcomes, which could influence economy, significantly. This paper presents a survey on the relationship between personality dimensions with behavioral biases and availability bias among investment managers in the Tehran Stock Exchange using SPSS software, descriptive and inferential statistics. The necessary data are collected through questionnaire and they are analyzed using some statistical tests. The preliminary results indicate that there is a relationship between personality dimensions and behavioral biases like conservatism bias and availability bias among the investors in the Tehran Stock Exchange.
\end{abstract}

\section{Introduction}

Investors are normally assumed to make their financial decisions rationally according to classical economic theories but some novice investors make unsuitable investment decisions based on irrational exuberance (Ricciardi, 2008). In fact, there are always some evidences on irregularity of stock market, there are various efforts on explaining the phenomena, which often follows different logic, and it is more associated with psychological characteristics describing investors' behaviors on capital markets (Slovic, 2001; Glaser et al., 2004; Jerzmanowski \& Nabar, 2008; Bosi \& Seegmuller, 2010). In many cases, investors are unaware of their own desires and make false financial decisions.

Corresponding author. Tel: +98-911-2828735

E-mail addresses: m.moradi@guilan.ac.ir (M. Moradi)

(C) 2013 Growing Science Ltd. All rights reserved.

doi: 10.5267/j.msl.2013.03.003 
If investors know themselves better and try to modify their biases, they can perform better also with having a systematic investment plan they can design an optimum portfolios. According to Slovic (2012) people's personality plays an important role on making financial decisions and as Adam Smith states "You are-face it-a bunch of emotions, prejudices, and twitches, and this is all very well as long as you know it. Successful speculators do not necessarily have a complete portrait of themselves, warts and all, in their own minds, but they do have the ability to stop abruptly when their own intuition and what is happening out there are suddenly out of kilter”.

Taylor (1975) investigated some of the implications of cognitive strain for decision-making effectiveness. He studied the effect of cognitive strain on narrowly constraining or "bounding" rational decision-making and criticized the choice strategies of satisficing as failing to broaden the bounds of rational decision-making. Barnewall (1987) investigated psychological characteristics of the individual investor and discussed how a good investment strategy could turn into failure by making emotional financial decisions. Mittal and Vyas (2008) performed an empirical study to investigate personality type and investment choice.

Pompian and Longo (2004) performed an empirical investigation on newly introduced paradigm for practical application of behavioral finance. In fact, they stated that the next phase in the practical application of behavioral finance would to correlate established investor biases with the psychographic and gender profiles of specific investors. Gharekolchian (2011) studied influencing factors on disposition effect in the Tehran Stock Exchange. She concluded that there was not any relationship between over confidence and mental accounting with disposition effect and conscientiousness had positive relationship with disposition effect but illusion of control had negative relationship with this effect. In addition, the relationship between educational background and disposition effect was negative, which means that with an increase on the levels of education, the amount of disposition effect can be diminished. In addition, the results showed that the amount of over confidence was more in men than women and the age group, 20 to 30 had more over confidence.

Bloomfield (2010) compared traditional and behavioral finance together in a three-dimensional model and concluded that there were many exceptions in financial markets, which were not justifiable based on traditional financial theories. Sedghi Khorasgani (2007) classified the investors of Tehran stock Market based on investment behavior's style into three categories including conservative, safe and assured people and people with absolutely risk. The results indicated that the $60 \%$ of investors in the Tehran Stock Exchange behaved conservatively, 30\% have assured behavior and 10\% were totally risky investors. In continue, researcher trough identification a number of common behavioral bias attempts to provide guidelines for better understanding of ordinary investors' decision making manner and with using of this understanding due to making better and more desirable investment decisions in Iranian Capital Market.

Bae and Nelson (2007) investigated whether permanent earnings growth, crucial to stock valuation, increased during the 1990s, as recommended by proponents of the new economy. They did not find strong evidence of either a one-time structural break or gradual change based on S\&P 500 earnings over the period 1951-2000. Nevertheless, the confidence interval on permanent earnings growth was wide enough to include an increase that was roughly consistent with the bull market of the late 1990s and the concluded that it was not possible to reject a rational basis for that exuberance.

This paper presents a survey on the relationship between personality dimensions with behavioral biases and availability bias among investment managers in the Tehran Stock Exchange. The organizational of this paper first presents details of the proposed study in section 2. Section 3 presents details of results and finally concluding remarks are given in the last to summarize the contribution of the paper. 


\section{The proposed study}

In this paper, we study the relationship between personality dimensions of investors with behavioral biases based on four dimensions of investor personality in Myers Briggs Type Indicator (MBTI). MBTI model defines four dimensions of investor personality including introversion versus extraversion, sensation versus intuition, thinking versus feeling and perceptual versus judgment and these four variables are considered as systematic errors in judgment. In this paper, range of behavioral biases is limited to 2 known commonly ones, which include conservatism bias and availability bias. The method of data collection in this paper is questionnaire and its statistical population includes individual investors of Tehran Stock Exchange. The scope place is Tehran and time interval is between December and January 2012. These variables are measured based on suggested questionnaire. For scoring the participants responses, in each question it is assumed that if a questioner believes selected question is related to behavioral bias, then we assign a score 2, otherwise score is equal to 1 . Those who gain scores above $50 \%$ of total number of related questions to each behavioral bias are talented of showing that's bias in their decision. We use SPSS software in order to evaluate hypotheses and data analysis and because variables maintain Nominal-Qualitative, Chisquare test and phi test are used for testing hypotheses.

\section{The results}

In this section, the results of Chi-square test and phi-test are presented to study the relationship between personality dimensions and behavioral biases of investors.

\subsection{The conservatism and personality dimensions relationship}

The personality dimensions with four components including sensation-intuition, feeling-thinking, perceptual-judgment, extroversion-introversion are evaluated in this survey. To study the effect of each related components of personality dimensions on conservatism we test four sub-tests. For investigating the relationship between two variables with nominal scale, we have used Chi-square test and correlation ratios. In this test, null hypothesis states that personality types is inconsistent with conservatism and the opposite hypothesis suggests that there is a correlation between personality's types and conservatism.

If the calculated significance level is equal or less than 0.05 , the null hypothesis will be rejected at least in 5\% significance level and opposite hypothesis will be accepted because of correlation. The calculated coefficient based on categories of considered variables, respectively or none respectively can be considered as an indicator of the correlation. Based on the results of phi correlation test, correlation between two sensation-intuition variables and conservatism with -0.28 also with calculated error level is 0.001 , which shows that null hypothesis is rejected in $1 \%$ significance level and the opposite hypothesis will be accepted because of correlation between two variables.

Correlation between two variables perceptual- judgment and conservatism with amount is equal to 0.156 and calculated error level is 0.055, which shows that null hypothesis cannot be rejected in 5\% significance level but in $90 \%$ assurance level it could be rejected and opposite hypothesis is confirmed because of correlation between them. Correlation ratios between two variables feelingthinking and extroversion-introversion with conservatism respectively are -0.077 and -0.079 , respectively where calculated error levels are bigger than 0.05 and 0.10 , which show that null hypotheses even at the $90 \%$ assurance level could not be rejected. As a result, the existence of significant correlation between mentioned relationships cannot be accepted. In other words, there are not any correlations between the variables, thinking-feeling and introversion-extroversion with conservatism. The results of correlation test between the related components to personality types with conservatism component are shown in Table 1. 


\section{Table 1}

The results of correlation test between the related components of personality types with conservatism component

\begin{tabular}{|c|c|c|c|c|c|c|}
\hline \multicolumn{2}{|l|}{ Variables } & \multicolumn{2}{|c|}{ Pearson Chi-Square } & \multicolumn{2}{|c|}{ Phi } & \multirow{2}{*}{ Result Hypothesis } \\
\hline Personality & Bias & Value & Asymp. Sig. (2-sided) & Value & Sig. & \\
\hline Sensation - Intuition & Conservatism & 11.838 & .001 & -.280 & .001 & Correlation coefficient is significant. \\
\hline Feeling-Thinking & Conservatism & .900 & .343 & -.077 & .343 & Correlation coefficient is not significant \\
\hline Judgment - Perceptual & Conservatism & 3.672 & $.055+$ & -.156 & .055 & Correlation coefficient is significant. \\
\hline Introversion-Extraversion & Conservatism & .936 & .333 & -.079 & .333 & Correlation coefficient is not significant \\
\hline
\end{tabular}

\subsection{The relation of behavioral bias of availability and personality dimensions}

In this section, personality dimensions with four components 'Sensation-Intuition', 'thinking-feeling', 'perceptual-judgment', 'extroversion-introversion' are evaluated. In this test, the null hypothesis indicates that personality types are not correlated with data availability and unlike that the opposite hypothesis suggests that there is a correlation between personality types and data availability.

If the calculated significance level is equal or less than 0.05 , the null hypothesis will be rejected at least when the level of significance is $5 \%$ and opposite hypothesis is accepted because of correlation. The calculated coefficient based on categories of considered variables respectively or none respectively can be considered as an indicator of the correlation. Based on the results of correlation Phi, correlation between two variables, 'extroversion-introversion' and data availability with -0.157 also with calculated error level is 0.055 , which shows that null hypothesis cannot be rejected at $5 \%$ significance level but in 10\% significance the opposite hypothesis is approved because of correlation.

Correlation between two variables 'Sensation-Intuition', 'Feeling- thinking', 'Perceptual- judgment' with data availability are $-0.045,0.081,0.009$, respectively. The calculated error level is larger than 0.05 and 0.10 , which shows that null hypothesis cannot be rejected when the level of significance is $10 \%$. As a result, the existence of significant correlation between mentioned relationships cannot be accepted. In other words, there is not any correlation between variables 'Sensation-Intuition', 'Feeling- thinking', 'Perceptual- judgment' with data availability. Table 2 shows the results of correlation test between the related components to personality types with availability component.

\section{Table 2}

The results of correlation test between the related components to personality types with availability component

\begin{tabular}{llccccc}
\hline \multicolumn{1}{c}{ Variables } & \multicolumn{2}{c}{ Pearson Chi-Square } & \multicolumn{2}{c}{ Phi } \\
Personality & Bias & Value & Asymp. Sig. (2-sided) & Value & Sig. & Result Hypothesis \\
\hline Sensation-Intuition & Availability & .312 & .576 & -.045 & .576 & Correlation coefficient is not significant \\
Feeling-Thinking & Availability & .986 & .321 & .081 & .321 & Correlation coefficient is not significant \\
Judgment - Perceptual & Availability & .011 & .916 & .009 & .916 & Correlation coefficient is not significant \\
Introversion-Extraversion & Availability & 3.727 & .054 & -.157 & .054 & Correlation coefficient is significant. \\
\hline
\end{tabular}

\section{Discussion and conclusion}

To examine two hypotheses of research we have used eight tests. All research hypotheses have been measured due to the nature of measurement and research objectives have been investigated with using of Chi-square correlation test and phi that summarized in Table 3. It can be concluded that there were some interrelationships between personality dimensions with perceptual illusion in Stock Exchange of Tehran. The results of first hypothesis also show that there was a relationship between extroversion-introversion and data availability bias, so it is suggested the authorities of Tehran Stock Exchange help to make the best investment decisions with increasing the information and, awareness to investors through publication of articles and books and hold seminars and classes in order to reduce this bias. In addition, with holding training courses reinforce the investors' spirit of realism and help them to adopt more optimal decisions. 
Table 3

Hypotheses, variables and the results of null and opposite hypotheses

\begin{tabular}{|c|c|c|c|c|c|c|}
\hline \multicolumn{2}{|c|}{ Research Hypotheses } & \multicolumn{2}{|c|}{ Research Variables } & \multicolumn{2}{|c|}{$\begin{array}{l}\text { Null hypotheses and } \\
\text { opposite }\end{array}$} & \multirow{2}{*}{ Result Hypotheses } \\
\hline $\begin{array}{l}\text { The main } \\
\text { hypothesis }\end{array}$ & $\begin{array}{c}\text { The Sub } \\
\text { hypothesis }\end{array}$ & The first variable & $\begin{array}{c}\text { The second } \\
\text { variable }\end{array}$ & $\phi=0$ & $\phi \neq 0$ & \\
\hline \multirow{4}{*}{ The first hypothesis } & First & Intuition - Sensation & Availability & $\checkmark$ & $x$ & $\begin{array}{l}\text { Correlation coefficient is not } \\
\text { significant }\end{array}$ \\
\hline & Second & Feeling-Thinking & Availability & $\checkmark$ & $x$ & $\begin{array}{c}\text { Correlation coefficient is not } \\
\text { significant }\end{array}$ \\
\hline & Third & Perceptual - Judgment & Availability & $\checkmark$ & $x$ & $\begin{array}{c}\text { Correlation coefficient is not } \\
\text { significant }\end{array}$ \\
\hline & Fourth & $\begin{array}{l}\text { Introversion- } \\
\text { Extraversion }\end{array}$ & Availability & $x$ & $\checkmark$ & $\begin{array}{c}\text { Correlation coefficient is } \\
\text { significant. }\end{array}$ \\
\hline \multirow{4}{*}{$\begin{array}{l}\text { The second } \\
\text { hypothesis }\end{array}$} & First & Intuition - Sensation & Conservatism & $x$ & $\checkmark$ & $\begin{array}{l}\text { Correlation coefficient is } \\
\text { significant. }\end{array}$ \\
\hline & Second & Feeling-Thinking & Conservatism & $\checkmark$ & $x$ & $\begin{array}{c}\text { Correlation coefficient is not } \\
\text { significant }\end{array}$ \\
\hline & Third & Perceptual - Judgment & Conservatism & $x$ & $\checkmark$ & $\begin{array}{c}\text { Correlation coefficient is } \\
\text { significant }\end{array}$ \\
\hline & Fourth & $\begin{array}{l}\text { Introversion- } \\
\text { Extraversion }\end{array}$ & Conservatism & $\checkmark$ & $x$ & $\begin{array}{l}\text { Correlation coefficient is not } \\
\text { significant }\end{array}$ \\
\hline
\end{tabular}

The results of the second hypothesis show that there was a relationship between Sensation-Intuition, and perceptual-judgment with conservatism bias so it is suggested the investment advisors help them reduce this bias with high quality and professional consultations.

\section{Acknowledgment}

The authors would like to thank the anonymous referees for constructive comments on earlier version of this paper.

\section{References}

Bae, J., \& Nelson, C.R. (2007). Earnings growth and the bull market of the 1990s: Is there a case for rational exuberance? Journal of Macroeconomics, 29(4), 690-707

Barnewall, M. M. (1987). Psychological characteristics of the individual investor. ICFA Continuing Education Series, 2, 62-71.

Bosi, S., \& Seegmuller, T. (2010). On rational exuberance. Mathematical Social Sciences, 59(2), 249270.

Gharekolchian, N. (2011). The study on effective factors on disposition effect in the Tehran Stock Exchange. M.A. Thesis, Tehran University.

Glaser, M., Nöth, M., \& Weber, M. (2004). Behavioral finance. Lehrstuhl für Allgemeine Betriebswirtschaftslehre, Finanzwirtschaft, insbesondere Bankbetriebslehre, Universität Mannheim.

Jerzmanowski, M., \& Nabar, M. (2008). The welfare consequences of irrational exuberance: Stock market booms, research investment, and productivity. Journal of Macroeconomics, 30(1), 111-133

Mittal, M., \& Vyas, R. K. (2008). Personality type and investment choice: An empirical study. The ICFAI University Journal of Behavioral Finance, 5(3), 7-22.

Pompian, M. M., \& Longo, J. M. (2004). A new paradigm for practical application of behavioral finance. The Journal of Wealth Management, 7(2), 9-15.

Ricciardi, V. (2008). The psychology of risk: The behavioral finance perspective. Handbook of Finance.

Sedghi Khorasgani, H. (2007). The dominant style of investors behavior in Tehran Stock Exchange. Capital Journal, 542, 18.

Slovic, P. (2001). Psychological study of human judgment: Implications for investment decision making. The Journal of Psychology and Financial Markets,2(3), 160-172. 
1196

Slovic, P. (2012). Psychological study of human judgment: Implications for investment decision making. The Journal of Finance, 27(4), 779-799.

Taylor, R. N. (1975). Psychological determinants of bounded rationality: Implications for decisionmaking strategies. Decision Sciences, 6(3), 409-429. 